Article

\title{
Single-Step Purification of Monomeric L-Selectin via Aptamer Affinity Chromatography
}

\author{
Christian Kuehne ${ }^{1, *}$, Stefanie Wedepohl ${ }^{2}$ and Jens Dernedde ${ }^{1}$ \\ 1 Institute of Laboratory Medicine, Clinical Chemistry and Pathobiochemistry, \\ Charité-Universitätsmedizin Berlin, 13353 Berlin, Germany; jens.dernedde@charite.de \\ 2 Institute of Chemistry and Biochemistry, Freie Universität Berlin, 14195 Berlin, Germany; \\ stefanie.wedepohl@fu-berlin.de \\ * Correspondence: christian.kuehne@charite.de; Tel.: +49-30-450-569-176
}

Academic Editor: Beate Strehlitz

Received: 22 December 2016; Accepted: 20 January 2017; Published: 24 January 2017

\begin{abstract}
L-selectin is a transmembrane receptor expressed on the surface of white blood cells and responsible for the tethering of leukocytes to vascular endothelial cells. This initial intercellular contact is the first step of the complex leukocyte adhesion cascade that ultimately permits extravasation of leukocytes into the surrounding tissue in case of inflammation. Here we show the binding of a soluble histidine tagged L-selectin to a recently described shortened variant of an L-selectin specific DNA aptamer with surface plasmon resonance. The high specificity of this aptamer in combination with its high binding affinity of $\sim 12 \mathrm{nM}$, allows for a single-step protein purification from cell culture supernatants. In comparison to the well-established Ni-NTA based technology, aptamer affinity chromatography (AAC) was easier to establish, resulted in a 3.6-fold higher protein yield, and increased protein purity. Moreover, due to target specificity, the DNA aptamer facilitated binding studies directly from cell culture supernatant, a helpful characteristic to quickly monitor successful expression of biological active L-selectin.
\end{abstract}

Keywords: L-selectin; aptamer; DNA; recombinant protein; purification; affinity; SPR

\section{Introduction}

Histidine tagged proteins are widely used in recombinant protein production as the purification of His-tagged proteins via Ni-NTA is a versatile and well established method [1,2]. However, to obtain pure and biologically active protein in adequate yields, optimization strategies are commonly necessary. Depending on the quality and quantity of unspecific protein binding from crude mixture to the Ni-NTA matrix, different approaches including competitor based binding and washing buffer compositions (e.g., imidazole, high salt, $\mathrm{pH}$, detergents) are needed, but might reduce the overall yield of the target protein. Protein purification via aptamer affinity chromatography (AAC) is an outstanding alternative, if appropriate [3]. The typically high affinity and specificity of aptamers result in high yields of pure protein due to very low unspecific binding [4,5]. Additionally, genetic engineering to equip the target protein with an affinity tag is dispensable. In contrast, for every new target, a suitable aptamer has to be created. A further problem might be the essential modification of the aptamer, to link the nucleic acid to a solid support. Slight modifications might change the aptamer structure and render the molecule inactive $[5,6]$.

Selectins are a family of membrane bound adhesion receptors that recognize the common tetrasaccharide ligand, sialyl Lewis X. Selectins are involved in the first steps of leukocyte adhesion, which lead to the guidance of immune cells out of the vasculature to sites of inflammation [7]. Neutralization of pathogens is their task in healthy individuals, but in pathological settings such as rheumatoid arthritis or phenomena like reperfusion injury, the migration of leukocytes from the 
blood stream to the tissues is dysregulated and contributes to damage healthy tissue as well [8]. Here the first step of the adhesion, the tethering of the leukocytes, is a hallmark for the cascade and mainly mediated by the selectins [7,9].

Besides E-selectin that is expressed on activated endothelium and P-selectin that can be found on both activated endothelium and platelets, L-selectin is produced by most leukocytes [10]. The L-selectin specific aptamer LD201 (39 bp) described by Hicke et al. [11] binds in a calcium dependent manner with nanomolar affinity. In 1999 Romig et al. already used a slightly shortened variant (36 bp, LD201mod) of the originally described aptamer for affinity purification of L-selectin IgG fusion protein from CHO cells [12]. An even shorter version of LD201, LD201m $\Delta 1$ (28 bp, Table 1), with comparable affinity but significant increase in stability (i.e., increased melting temperature) was recently described [13]. In this study, we used the $5^{\prime}$ biotinylated LD $201 \mathrm{~m} \Delta 1$ for purification of the monomeric, C-terminal histidine-tagged human L-selectin consisting of the N-terminal Lectin and EGF-like domain (LE-His) from cell culture supernatant. Purification was achieved in a single step. Moreover, calibration-free concentration analysis and affinity determination was possible directly from the crude supernatant by surface plasmon resonance.

Table 1. Sequences of the various shortened variants of the originally described aptamer.

\begin{tabular}{|c|c|c|}
\hline Aptamer & Sequence & Reference \\
\hline LD201 & 5'-CAAGGTAACC AGTACAAGGT GCTAAACGTA ATGGCTTCG-3' & Hicke et al. 1996 \\
\hline LD201mod & 5'-GCGGTAACC AGTACAAGGT GCTAAACGTA ATGGCGC-3' & Romig et al. 1999 \\
\hline $\mathrm{LD} 201 \mathrm{~m} \Delta 1$ & $5^{\prime}$-GC $\cdots$ C AGTACAAGGT GCTAAACGTA ATGGC-3' & Riese et al. 2016 \\
\hline
\end{tabular}

\section{Materials and Methods}

\subsection{Protein Expression}

L-selectin LE-His was transiently expressed using the HEK 293-F expression system (Life Technologies, Carlsbad, CA, USA) as described before [14]. Briefly, LE-His inserted in a pcDNA3 vector (Life Technologies, Carlsbad, CA, USA) was used to transfect $500 \mathrm{~mL}$ of 293-F cell suspension at a density of $1 \times 10^{6}$ cells per $\mathrm{mL}$. After $72 \mathrm{~h}$ of incubation at $37^{\circ} \mathrm{C}, 8 \% \mathrm{CO}_{2}$, and shaking at $90 \mathrm{RPM}$ the cell culture supernatant was harvested by centrifugation at $4{ }^{\circ} \mathrm{C}$ and $6000 \times g$ for 20 min and subsequently processed by sterile filtration.

\subsection{Preparation of the Aptamer Column}

$550 \mu \mathrm{g}$ of biotinylated L-selectin aptamer LD201m $\Delta 1$ (Metabion, Steinkirchen, Germany) were coupled to $1 \mathrm{~mL}$ streptavidin agarose (Thermo Fisher Scientific, Waltham, MA, USA) using PBS with $500 \mathrm{mM} \mathrm{NaCl}$ as coupling buffer. Prior to coupling, streptavidin agarose was washed at least five times with coupling buffer before incubation with the aptamer for $2 \mathrm{~h}$ at room temperature. Coupling efficiency was monitored by A260 absorption of the supernatant (data not shown).

\subsection{Purification of L-Selectin LE-His}

For comparison three different purification strategies were performed via gravity flow columns at room temperature without the supplementation of DNase inhibitors to the cell culture supernatant to avoid potential aptamer degradation (A: aptamer, B: Ni-NTA, non-optimized, C: Ni-NTA, optimized procedure). Resin capacities were determined using very small column volumes (i.e., $50 \mu \mathrm{L}$ ) and an excess of cell culture supernatant to fully load the resins, keeping unspecific binding at a minimum. The amount of L-selectin bound to the resin was subsequently determined by ELISA. The column volumes were adjusted according to the resin capacities (capacity Ni-NTA: $0.46 \mathrm{mg} / \mathrm{mL}$ and aptamer: $0.32 \mathrm{mg} / \mathrm{mL}$; column volume Ni-NTA: $0.695 \mathrm{~mL}$; and aptamer: $1 \mathrm{~mL}$ ). Columns were equilibrated with an excess of appropriate binding buffer (A, PBS +/+, i.e., with $0.9 \mathrm{mM} \mathrm{CaCl}$, and $0.5 \mathrm{mM} \mathrm{MgCl}_{2}$; 
B, PBS $-/-;$ C, PBS $-/-+20 \mathrm{mM}$ imidazole). Prior to loading the cell culture supernatant to Ni-NTA columns the supernatant was supplemented with $1 \mathrm{mM} \mathrm{NiSO}_{4}$ to avoid Ni-ion leaching from the column and for optimized procedure additionally $20 \mathrm{mM}$ imidazole were included. The flow through was collected and the columns were washed with 30 column volumes $(\mathrm{CV})$ washing buffer each (A, PBS +/+; B, PBS - / + + $10 \mathrm{mM}$ imidazole; C, PBS - / - + $500 \mathrm{mM} \mathrm{NaCl}+40 \mathrm{mM}$ imidazole). Bound protein was eluted with five CV of elution buffer each (A, PBS - / - + $100 \mathrm{mM}$ EDTA; B and C, PBS - / - + $250 \mathrm{mM}$ imidazole).

\subsection{Endoglycosidase Digestion}

Endoglycosidase digestion with PNGase F was performed as described previously [14]. Briefly, glycosylated L-selectin LE-His was denatured at $95{ }^{\circ} \mathrm{C}$ for $5 \mathrm{~min}$ in the presence of $1 \%$ SDS $(w / v)$ and 10\% 2-mercaptoethanol. After diluting the mixture 1/10, $100 \mathrm{mU}$ PNGase F (Roche Applied Science, Mannheim, Germany) were added and incubated for $16 \mathrm{~h}$ at $37^{\circ} \mathrm{C}$.

\subsection{SDS-PAGE Staining and Western Blotting}

The purity of the LE-His protein was analyzed under non-reducing conditions on a $13 \%$ polyacrylamide gel and visualized by silver staining. Identity of L-selectin was confirmed by Western blotting with subsequent immunodetection using standard protocols with monoclonal antibody DREG-200 (self-prepared from hybridoma) as primary antibody and a goat-anti-mouse HRP-conjugate (Dako, Glostrup, Denmark) as secondary antibody.

\subsection{Selectin Quantification via ELISA and SPR}

LE-His was quantified by a sandwich ELISA using DREG-200 as capture and biotinylated DREG-55 (self-prepared from hybridoma with subsequent biotinylation) as detection antibody following standard procedures, whereas human serum (Thermo Fisher Scientific, Dreieich, Germany) served as a standard.

Selectin concentration from the cell culture supernatant was additionally determined using calibration free concentration analysis provided by the Biacore X100 with plus package (GE Healthcare, Freiburg, Germany). Here, only the active protein that is able to bind the aptamer is considered. In this set-up, samples are injected at flow rates of $10 \mu \mathrm{L} / \mathrm{min}$ and $100 \mu \mathrm{L} / \mathrm{min}$ under mass transfer limitation. Therefore, biotinylated LD201m $\Delta 1$ was coupled to $1900 \mathrm{RU}$ to a streptavidin chip (GE Healthcare, Freiburg, Germany). The reference lane was left untreated. By providing information about the mass $(32,114 \mathrm{Da})$ and the diffusion coefficient $\left(8.5 \times 10^{-11} \mathrm{~m}^{2} \cdot \mathrm{s}^{-1}\right)$ of the analyte, the built-in software of the Biacore X100 calculates protein concentrations from the slope differences [15-17]. HBS-Ca (20 mM HEPES, pH 7.5, $150 \mathrm{mM} \mathrm{NaCl}$ and $1 \mathrm{mM} \mathrm{CaCl}_{2}$ ) was used as running buffer, $100 \mathrm{mM}$ EDTA as regeneration buffer and cell culture medium of untransfected HEK cells was used as a blank.

\subsection{Affinity Determination via SPR}

Binding affinities of L-selectin LE-His to aptamer LD201m $\Delta 1$ were measured by kinetic titration series using a Biacore X100 with plus package (GE Healthcare, Freiburg, Germany). A series of five sample dilutions was injected at a flow rate of $30 \mu \mathrm{L} / \mathrm{min}$ over biotinylated LD201m $\Delta 1$ coupled to a streptavidin chip (61.4 RU immobilized) (GE Healthcare, Freiburg, Germany) and a mock treated reference lane using running buffer and blanks as mentioned above. Data were analyzed by built-in software of the Biacore X100 [18] providing analyte concentrations as determined by the above mentioned quantification method via SPR. 


\section{Results and Discussion}

\subsection{Protein Purification by Ni-NTA and AAC}

For better comparison of Ni-NTA and AAC based purification strategies, column capacities were determined prior to protein clean up. Therefore, small columns (50 $\mu \mathrm{L}$ column volume) were run with an excess of cell culture supernatant $(100 \mathrm{~mL})$ to keep unspecific binding to both columns at a minimum (data not shown). Larger columns were run after adjustment of the column volume according to the calculated capacities to match the capacity of each column material.

Purification of the monomeric L-selectin LE-His via Ni-NTA by standard procedures as recommended by the manufacturer (Qiagen, Hilden, Germany) did not produce satisfying results in a one-step purification procedure under standard, un-optimized conditions (Figure 1A). The addition of $20 \mathrm{mM}$ imidazole to the supernatant and column washing with increased salt and imidazole concentration (PBS $-/-+500 \mathrm{mM} \mathrm{NaCl}+40 \mathrm{mM}$ imidazole) significantly contributed to shield unspecific binding and resulted in highly pure LE-His protein. In contrast, AAC yielded highly pure L-sel LE-His within one step without the need for further optimization (Figure 1C). Digestion with the endoglycosidase PNGaseF revealed the differently glycosylated isoforms of the L-selectin including the non-glycosylated, fastest migrating protein (Figure 1B) [14].

A

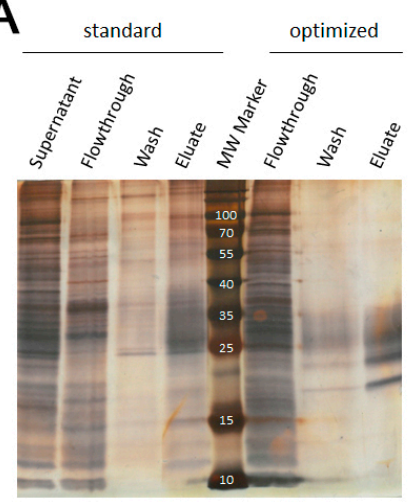

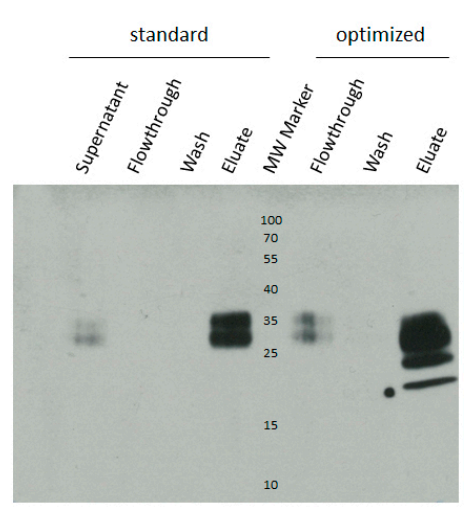

B

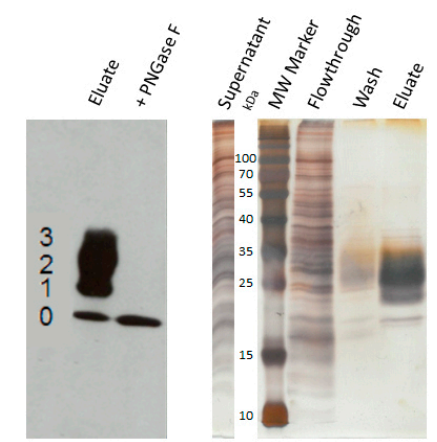

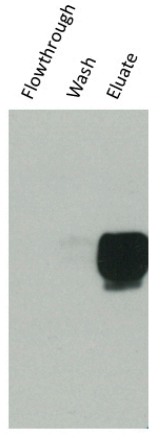

Figure 1. Verification of protein purity and identity after (A) Ni-NTA chromatography. Left, silver stained SDS-PAGE and right, respective immunoblot detecting L-selectin LE-His. Standard and optimized purification protocols are compared. The molecular weight (MW) marker is given in kDa; (B) Endoglycosidase digest of elute. Numbers indicate the different glycoforms of L-selectin LE-His, 0: no $N$-glycans, 1: one $N$-glycan, 2: two $N$-glycans, 3: three $N$-glycans; (C) AAC chromatography. Left, silver stained SDS-PAGE and right, respective immunoblot detecting L-selectin LE-His. The molecular weight (MW) marker is given in $\mathrm{kDa}$.

\subsection{Aptamer Affinity to L-Selectin}

The originally described aptamer binds to L-selectin with low nanomolar affinity [11]. To determine if the shortened $28 \mathrm{bp}$ variant maintains this high affinity binding, SPR analyses were performed. Ascending concentrations of purified monomeric L-selectin (LE-His) cell culture supernatant were injected in a single run (single cycle kinetics; SCK; Figure 2A) over the biotinylated and immobilized L-selectin aptamer LD201m $\Delta 1$, resulting in an affinity of $K_{D}=11.2 \pm 0.8 \mathrm{nM}$ (Figure 2B). Related to the original full length aptamer that showed an affinity of $1.8 \mathrm{nM}$ to dimeric L-selectin Fc-chimera in a filter binding assay [11], this is a comparable result. Prior to the affinity measurement, the concentration of L-selectin LE-His in the cell culture supernatant was determined by a calibration free SPR method (calibration-free concentration analysis; CFCA; Figure 3) [15-17] yielding a concentration of $200 \pm 0.25 \mathrm{nM}$ (SD from duplicate). Interestingly, aptamer degradation by DNase seems not to be a major problem, as recognized by the comparable resonance units obtained during CFCA. Given a total volume of $150 \mathrm{~mL}$ and a molecular mass of 32,114 g/mol for the fully glycosylated protein, a total 
amount of $963 \mu \mathrm{g}$ was found by CFCA which is in good agreement with $988 \mu \mathrm{g}$ determined by the ELISA method. Purification via AAC was able to clean up to four-fold the amount of protein compared to the optimized Ni-NTA procedure (Table 2).
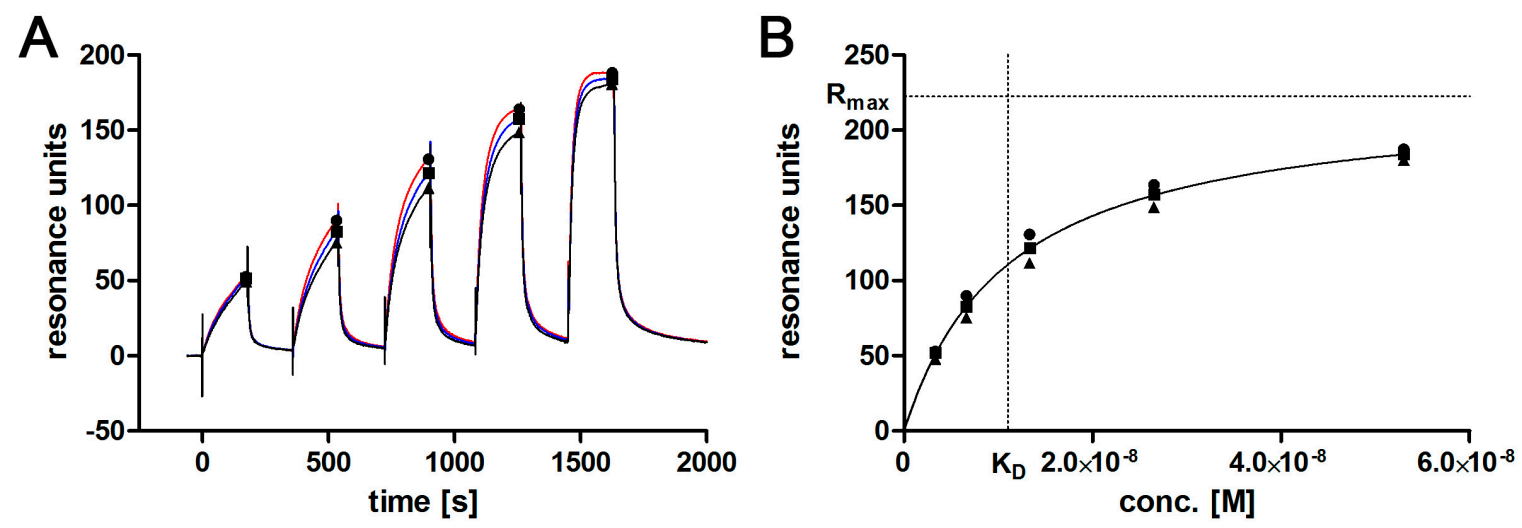

Figure 2. Single cycle kinetics of L-selectin LE-His in cell culture supernatant using SPR. (A) triplicate of the kinetic titration is shown. Symbols mark binding levels that will be plotted against the respective concentrations shown in (B) binding levels are plotted against corresponding concentrations. Extrapolated $R_{\max }$ and respective $\mathrm{K}_{\mathrm{D}}$ at $\mathrm{R}_{\max } / 2$ are marked by dotted lines.

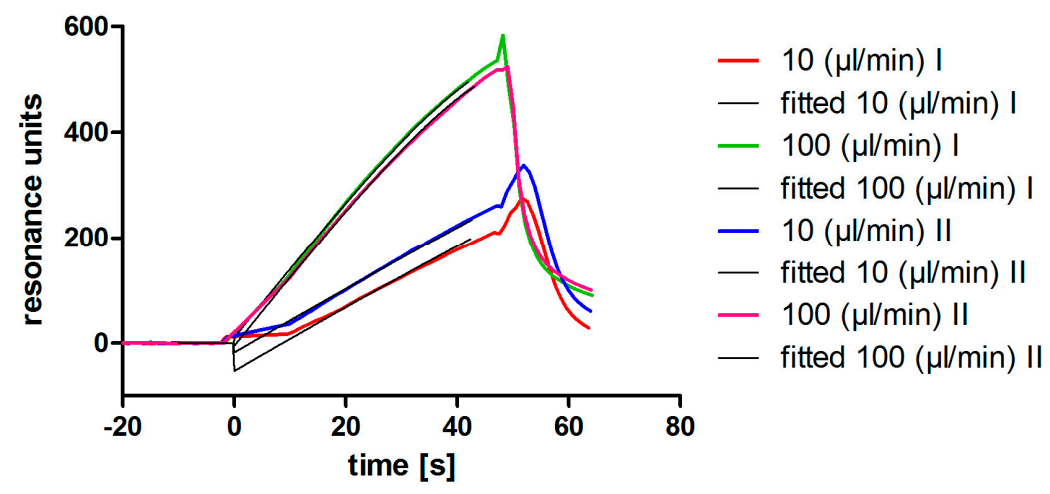

Figure 3. Calibration free concentration analysis using SPR. L-selectin LE-His in cell culture supernatant was analyzed in duplicate. The sensorgrams (colored lines) and the fits (black lines) at the different flowrates are shown.

Table 2. Affinity matrix performance. (a) amount of L-sel LE-His from cell culture supernatant bound to 1 eq. Ni-NTA or 1 eq. aptamer LD201m $\Delta 1$ (ELISA data) ${ }^{\text {(b) }}$ yield calculated by the total amount of L-sel LE-His in $150 \mathrm{~mL}$ cell culture supernatant $(988 \pm 276 \mu \mathrm{g}) ; \pm \mathrm{SD}$ from $\mathrm{N}=2$ in duplicates.

\begin{tabular}{ccc}
\hline Affinity Matrix & L-Sel LE-His $(\boldsymbol{\mu g})^{(\mathbf{a})}$ & Yield $^{(\%)}{ }^{(\mathbf{b})}$ \\
\hline Ni-NTA & $167 \pm 21$ & 17 \\
LD201m $\Delta 1$ & $608 \pm 23$ & 62 \\
\hline
\end{tabular}

\section{Conclusions}

The shortened aptamer variant $\mathrm{LD} 201 \mathrm{~m} \Delta 1$ shows binding comparable to the originally described aptamer [11] that is specifically targeting the leukocyte adhesion receptor, L-selectin, with low nanomolar affinity. The successful application as a blocking agent of leukocyte adhesion [13] and the detachment of the protein from the aptamer by complexation of divalent cations with EDTA strongly suggests a binding mode that involves the $\mathrm{Ca}^{2+}$ binding lectin domain. Biotinylation of the DNA aptamer at the $5^{\prime}$ end did not alter target recognition. Its high affinity and selectivity makes 
the synthetic ligand perfectly suitable to capture L-selectin from crude mixtures like cell culture supernatant. In contrast to standard affinity chromatography approaches for protein purification such as Ni-NTA, AAC does not rely on time consuming optimization procedures and the purified protein can be obtained in a single step in higher yields.

Acknowledgments: This work was generously supported by the Deutsche Forschungsgemeinschaft (DFG) by grants to the SFB 765. We kindly thank E.C. Butcher for providing DREG-200 and DREG-55 hybridoma.

Author Contributions: C.K., S.W. and J.D. conceived and designed the experiments; C.K. performed the experiments; C.K., S.W. and J.D. analyzed the data; S.W. contributed materials; C.K. and J.D. wrote the paper.

Conflicts of Interest: The authors declare no conflict of interest.

\section{References}

1. Porath, J.; Carlsson, J.; Olsson, I.; Belfrage, G. Metal chelate affinity chromatography, a new approach to protein fractionation. Nature 1975, 258, 598-599. [CrossRef] [PubMed]

2. Hage, D.S.; Matsuda, R. Affinity chromatography: A historical perspective. Method. Mol. Biol. 2015, 1286, 1-19. [CrossRef]

3. Zhao, Q.; Wu, M.; Chris, L.X.; Li, X.-F. Applications of aptamer affinity chromatography. $\operatorname{Tr} A C$ Trends Anal. Chem. 2012, 41, 46-57. [CrossRef]

4. Keefe, A.D.; Pai, S.; Ellington, A. Aptamers as therapeutics. Nat. Rev. Drug Discov. 2010, 9, 537-550. [CrossRef] [PubMed]

5. Acquah, C.; Danquah, M.K.; Yon, J.L.; Sidhu, A.; Ongkudon, C.M. A review on immobilised aptamers for high throughput biomolecular detection and screening. Anal. Chim. Acta 2015, 888, 10-18. [CrossRef] [PubMed]

6. Hianik, T.; Ostatna, V.; Zajacova, Z.; Stoikova, E.; Evtugyn, G. Detection of aptamer-protein interactions using QCM and electrochemical indicator methods. Bioorg. Med. Chem. Lett. 2005, 15, 291-295. [CrossRef] [PubMed]

7. Ley, K.; Laudanna, C.; Cybulsky, M.I.; Nourshargh, S. Getting to the site of inflammation: The leukocyte adhesion cascade updated. Nat. Rev. Immunol. 2007, 7, 678-689. [CrossRef] [PubMed]

8. Muller, W.A. Leukocyte-endothelial cell interactions in the inflammatory response. Lab. Investig. 2002, 82, 521-533. [CrossRef]

9. Sperandio, M.; Pickard, J.; Unnikrishnan, S.; Acton, S.T.; Ley, K. Analysis of leukocyte rolling in vivo and in vitro. Method. Enzymol. 2006, 416, 346-371.

10. Ley, K. The role of selectins in inflammation and disease. Trends Mol. Med. 2003, 9, 263-268. [CrossRef]

11. Hicke, B.J.; Watson, S.R.; Koenig, A.; Lynott, C.K.; Bargatze, R.F.; Chang, Y.F.; Ringquist, S.; Moon-McDermott, L.; Jennings, S.; Fitzwater, T.; et al. DNA aptamers block L-selectin function in vivo. Inhibition of human lymphocyte trafficking in scid mice. J. Clin. Investig. 1996, 98, 2688-2692. [CrossRef] [PubMed]

12. Romig, T.S.; Bell, C.; Drolet, D.W. Aptamer affinity chromatography: Combinatorial chemistry applied to protein purification. J. Chromatogr. B Biomed. Sci. Appl. 1999, 731, 275-284. [CrossRef]

13. Riese, S.B.; Buscher, K.; Enders, S.; Kuehne, C.; Tauber, R.; Dernedde, J. Structural requirements of mono-and multivalent L-selectin blocking aptamers for enhanced receptor inhibition in vitro and in vivo. Nanomed. Nanotechnol. Biol. Med. 2016, 12, 901-908. [CrossRef] [PubMed]

14. Wedepohl, S.; Kaup, M.; Riese, S.B.; Berger, M.; Dernedde, J.; Tauber, R.; Blanchard, V. N-glycan analysis of recombinant L-selectin reveals sulfated GalNac and GalNac-GalNac motifs. J. Proteome Res. 2010, 9, 3403-3411. [CrossRef] [PubMed]

15. Christensen, L.L. Theoretical analysis of protein concentration determination using biosensor technology under conditions of partial mass transport limitation. Anal. Biochem. 1997, 249, 153-164. [CrossRef] [PubMed]

16. Richalet-Secordel, P.M.; Rauffer-Bruyere, N.; Christensen, L.L.; Ofenloch-Haehnle, B.; Seidel, C.; van Regenmortel, M.H. Concentration measurement of unpurified proteins using biosensor technology under conditions of partial mass transport limitation. Anal. Biochem. 1997, 249, 165-173. [CrossRef] [PubMed] 
17. Sigmundsson, K.; Másson, G.; Rice, R.; Beauchemin, N.; Öbrink, B. Determination of active concentrations and association and dissociation rate constants of interacting biomolecules: An analytical solution to the theory for kinetic and mass transport limitations in biosensor technology and its experimental verification. Biochemistry 2002, 41, 8263-8276. [CrossRef] [PubMed]

18. Karlsson, R.; Katsamba, P.S.; Nordin, H.; Pol, E.; Myszka, D.G. Analyzing a kinetic titration series using affinity biosensors. Anal. Biochem. 2006, 349, 136-147. [CrossRef] [PubMed]

(C) 2017 by the authors; licensee MDPI, Basel, Switzerland. This article is an open access article distributed under the terms and conditions of the Creative Commons Attribution (CC BY) license (http://creativecommons.org/licenses/by/4.0/). 